\title{
LA INTERDEPENDENCIA DE LA DEMOCRACIA Y LOS PROCESOS DE INTEGRACIÓN
}

Por Abog. Roberto Herrera Cáceres, Ph.D. de la Universidad de Derecho, Economía y Ciencias Sociales de París, Francia; Ex profesor Investigador, Instituto de Investigación Jurídica, Universidad Nacional Autónoma de Honduras.

\section{Resumen}

El avance de la democracia en diferentes regiones y el acceso a las nuevas tecnologías de comunicación ha dado como resultado sociedades con alta exigencia hacia sus gobernantes y procesos de participación política.

La interdependencia como producto de los procesos globales tanto económicos, sociales como políticos ha generado una serie de demandas sociales sobre la eficiencia de sus gobiernos en cuanto al uso y administración de sus finanzas para el desarrollo, identificando cada vez más a los constructores de agendas sociales cercanas a los pueblos y su integración nacional y regional.

El presente documento, cita sendos procesos de Integración Regional Centroamericana que han iniciado una ruta al desarrollo interdependiente a través del proceso de desarrollo regional participativa, el cual si bien es cierto está en un modelo inicial e inspirador, se ha vuelto cada vez más pragmático y directo por sus resultados y filosofía, planteando al final un modelo de estado moderno y representativo y jamás fallido como lo platean algunos críticos sociales

Palabras clave: Interdependencia, agenda nacional, democracia, participación, Integración, Supranacionalidad.

\section{Abstract}

The advance of democracy in different regions and access to new communication technologies has resulted in societies with high demands to their governments and a political participation process.

Interdependence as a result of social, economic and political global processes has generated a series of social demands on the efficiency of their governments on the use and management of their development finance, identifying promoters of social agendas which are closer to communities and national and regional integration.

This paper cites two separate regional integration processes in Central America which have initiated a route to the interdependent development through participatory regional development process, which although it is in an initial and inspiring model has become increasingly pragmatic and direct due to its results and philosophy, presenting at the end, a model of a modern and representative state which has never failed as has been stated by some social

Keywords: Interdependence, national agenda participation, democracy, integration, supranational. 


\section{INTRODUCCIÓN 1}

Existe una interdependencia e interacción entre democracia e integración que se evidencia en la potenciación del desarrollo humano sostenido y sostenible de los pueblos y de un mejor aprovechamiento de los espacios positivos de los cambios globales ${ }^{2}$. Esa interdependencia e interacción no tiene un modelo acabado en el mundo porque ni la democracia ni la integración tienen una teoría de aplicación universal aunque si principios o valores ${ }^{3}$ que gozan de aceptación generalizada ${ }^{4}$.

El análisis de la relación entre la democracia y la integración implica tener presente la forma del Estado y de su régimen político y su relación con la calidad de vida del pueblo, y la complementación de esta relación, con mecanismos y procedimientos para lograrlos, con otros Estados y sus habitantes ${ }^{5}$. En efecto, hay fehaciente reconocimiento internacional sobre la vinculación indisoluble de los principios que salvaguardan la dignidad humana y los fundamentos de toda sociedad democrática; y de la relación entre democracia y derechos humanos, incluyendo el derecho al desarrollo y el Estado de Derecho. Relación que los refuerza mutuamente y evidencia su interdependencia. Esos principios y valores son fundamentales, universales e indivisibles y deben, como tales, guiar las democracias nacionales y las relaciones internacionales incluyendo a las organizaciones internacionales ${ }^{6}$.

Hay evidencias en cuanto a lo positivo de la influencia recíproca de democracia e integración en el caso de Estados desarrollados y el proceso de integración en que participan (como en el caso de la Unión Europea por su régimen y procedimientos democráticos y por su consistencia democrática básica y efectiva que se exterioriza en el bienestar

1) El autor del presente estudio ha efectuado varios análisis vinculados a la democracia que se relacionarán en el curso del presente estudio y publicado recientemente artículos sobre los aspectos básicos de la democracia nacional e internacional.

2) Kunhardt (Ludger), THE GLOBAL PROLIFERATION OF REGIONAL INTEGRATION European experience and Worldwide Trends, pag.5 - 58, Center for European Integration 3tudies, Bonn, Germany, 2004.

3) VILLORO (Luis), EL PODER Y EL VALOR, Fundamentos de una Ética Política, pp.333 $\neg 358$, El Colegio Nacional, Fondo de Cultura Eco-nómica, México, 1997.

4) Sobre un enfoque nacional, centroamericano e internacional de la democracia: V. Herrera Cáceres (H. Roberto), Desafíos y Estrategias de las Democracias de la Región frente al = proceso Soviético en Centro de Estudios Internacionales - Foro Interamericano, LA PERSTROIKA Y LA AMERICA LATINA, pp. 155 - 167, Tercer Mundo Editores, Colombia, 1989; V. También Herrera Cáceres (H. Robe o) Democracia y Paz - La Situación Centroamericana, la Guerrilla y el Terrorismo en Centro de Estudios Internacionales - Foro Interamericano, DEMOCRACIA 2000. Los grandes desafíos en América Latina, pp. 29-70, Fundación Simón Bolívar, Tercer Mundo Editores, Colombia, 1991

5 ) “The value of regional integration has to be Judged in itself through the prism of the people and countries involved". See Kunhardt (Lu jger), Op.Cit. p.59

6) La democracia está centrada en la promoción de la dignidad humana. Es la voluntad del pueblo que la asume como sistema de vida y es la voluntad de los Estados que lleva a expresarla en las relaciones internacionales. "Reconociendo que los derechos humanos, el estado de derecho y la democracia están relacionados entre si, se refuerzan mutuamente y se cuentan entre los valores y principios fundamentales, universales e indivisibles de las Naciones Unidas: Subrayando que la democracia el desarrollo y el respeto de todos los derechos humanos y las libertades fundamentales son interdependientes y se refuerzan mutuamente", Asamblea General (ONU), Resolución "Apoyo del sistema de las Naciones Unidas a los esfuerzos de los gobiernos para la promoción y la consolidación de las democracias nuevas o restauradas" A RES/61/22) de 14 de marzo de 2007. Ver también Declaración Universal sobre la Democracia. 
general de sus habitantes. Se trata de sociedades más estructuradas, igualitarias y participativas que propician una cohesión social más sólida en comparación con las de países subdesarrollados como los latinoamericanos. Esas características sociales determinan la estabilidad de las democracias en dichos Estados y su relación y proyección en la integración con otros Estados; integración que, a su vez, fortalece las democracias nacionales, por la vía de la cooperación internacional, y la democracia universal.

Así la democracia como objetivo y modo de gobierno es ejemplo que se busca asegurar y mejorar por medio de igual ideología y conductas democráticas, en los ámbitos nacionales y en los procesos de integración entre Estados de diferentes latitudes geográficas y niveles de desarrollo que siguen valores y principios comunes universalmente aceptados y que buscan reafirmar su respeto por los derechos humanos fundamentales y el imperio del Derecho incluyendo el derecho al desarrollo. Lo destacable es que la democracia está internacionalmente reconocida como un derecho fundamental de la ciudadana y del ciudadano, inseparable de todos los demás derechos humanos y de su aplicación efectiva nacional e internaciona. $\mathrm{I}^{7}$ En efecto, la democracia es responsabilidad nacional e internacional de los Estados que, por medio de un modo de gobierno apropiado, debe hacerse efectiva progresivamente como ideal universal y objetivo compartido, en respuesta del cumplimiento del derecho humano fundamental del ciudadano o ciudadana a esa democracia.

Sin embargo, la cuestión primordial está en el enfoque integral de la democracia en nuestros tiempos ${ }^{8}$, en los cuales la democracia instrumental, de procedimientos o electoral como legitimidad de origen necesita tomar sentido y duración expresándose en ejercicio permanente y creciente, como democracia sustantiva en beneficio del bien común de los habitantes y de la cohesión social consiguiente.

Una democracia así concebida para ser efectiva requiere que su ideal u objetivo sea puesto en ejecución con una forma de gobierno acorde para ello en un proceso permanente de interacciones entre el Estado y sus habitantes, asegurando que cuando estos participan en esquemas de integración, el credo democrático que los caracteriza contribuya a legitimar e impulsar el proceso integrador manteniéndolo centrado en la promoción y respeto de la dignidad humana, lo que es garantía de éxito de una integración efectiva. El resultado progresivo de ese proceso de integración contribuye asimismo a la cohesión social y la estabilidad política para la consolidación democrática de los Estados miembros.

\footnotetext{
${ }^{7}$ V. Declaración Universal sobre la Democracia; V. también Resolución sobre "fortalecimiento de la participación popular, la equidad, la justicia social y la no discriminación como bases esenciales de la democracia". Resolución de la Comisión de Derechos Humanos 2000/ 47 de 25 de abril 2000.

${ }^{8}$ PNUD, La Democracia en América Latina hacia un democracia de ciudadanas y ciudadanos, Informe del Programa de las Naciones Unidas para el Desarrollo, impreso por World Chile S.A., 2004. V. también TIRACO MEJÍA (Álvaro), INTEGRACION y DEMOCRACIA EN AMERICA LATINA y ÉL CARIBE BID - Intal, Buenos Aires, Argentina, noviembre 1997.
} 


\section{I.- LA DEMOCRACIA COMO IDEAL Y FORMA DE GOBIERNO}

La democracia ${ }^{9}$ como forma de gobierno tiene como agente y beneficiario al pueblo como soberano en el Estado del cual deriva la autoridad pública. De ahí que las elecciones auténticas, libres, justas y periódicas, ${ }^{10}$ de los ciudadanos o ciudadanas que ejercerán esa autoridad, constituya una de las características singulares y fundamentales de la democracia, como legitimación de origen (Representatividad). Sin perjuicio de ello, la democracia debe tener una legitimidad de ejercicio permanente que la haga efectiva materializando progresivamente el bien común, y lo que necesita acreditarse cotidianamente con la participación de los habitantes y su bienestar progresivo (legitimidad de ejercicio, rendición de cuentas y participación social).

En una sociedad democrática deben prevalecer los principios de libertad, igualdad, paz, justicia, responsabilidad y solidaridad de los seres humanos. Esos principios que conjugan en la sustentación de la dignidad humana, tienen su expresión en la vigencia efectiva de todos los derechos humanos por lo que las limitaciones a esos derechos humanos tienen que ser compatibles con la democracia que asegura el reconocimiento y respeto de los derechos y libertades de todas y todos y la ética, el orden público, el bienestar general y la seguridad en la sociedad. Así está universalmente reconocido en la Declaración Universal de Derechos Humanos, ${ }^{11}$ el Pacto Internacional de Derechos Económicos, Sociales y Culturales; ${ }^{12}$ y el Pacto internacional de Derechos Civiles y Políticos $^{13}$.

El derecho al desarrollo como derecho humano inalienable fue proclamado, por la Asamblea General de la ONU, en $1986^{14}$ afirmando la interdependencia de todos los derechos humanos (civiles, políticos, económicos, sociales, culturales incluyen el derecho al desarrollo) en medio de un debate entre Estados que consideraban que era necesario ejercer primero los derechos civiles y políticos para luego lograr los derechos económicos, sociales y culturales incluyendo el derecho al desarrollo, y otros que consideraban que, estos últimos derechos debían preceder de los derechos civiles y políticos. La interdependencia de los derechos humanos fue objeto de un proceso de consolidación cuyos hitos fundamentales se encuentran, entre otras, en la Conferencia Mundial de Derechos Humanos en cuya Declaración y Programa de Acción de Viena se reafirma la interrelación indisoluble de todos esos derechos humanos y la proclamación que la democracia, el desarrollo y el respeto de los

\footnotetext{
${ }^{9}$ V. Democracia y democratización: teoría y procesos, en GARRETON (Manuel Antonio), POLITICA y SOCIEDAD ENTRE DOS EPOCAS, América Latina en el cambio del siglo, pp. 65-91, Homo Sapiens Editores, Rosario, Argentina, 2000.

${ }^{10}$ V. Declaración sobre los Criterios para lecciones Libres y Justas, Consejo Interparlamentario, 154 reunión, Paris, 26 de marzo de 1994.

${ }^{11}$ Párrafos primero y quinto del preámbulo; Artículos 1 y 29 No. 2 de la Declaración.

${ }^{12}$ Párrafos primero, segundo, tercero y quinto del preámbulo; Artículo 4 del Pacto Internacional de Derechos Economicos.

${ }^{13}$ Párrafos primero, segundo, tercero y quinto del Preámbulo; Artículos 14 No. 1 y Art. 21 del Pacto.

${ }^{14}$ Resolución 41/128 de 4 de diciembre de 1996
} 
derechos humanos y libertades fundamentales son conceptos interdependientes que se refuerzan mutuamente. La aprobación, por la Asamblea General de la ONU, en 1997, de la Resolución sobre "Un Programa de Desarrollo ${ }^{15}$ destaca la vinculación entre desarrollo y derechos humanos y se señala, el respeto a esos derechos, como uno de los fundamentos indispensables del desarrollo, así como para la existencia de instituciones democráticas y eficaces, la lucha contra la corrupción, la representación transparente y la gestión pública responsable, la participación popular, la independencia del sistema judicial, el imperio de la ley y la paz civil.

En la Declaración del Milenio, ${ }^{16}$ los Jefes de Estado y de Gobierno consignaron valores y principios comunes que se orientan a ese sistema internacional democrático, al señalar que la conversión de la globalización debe convertirse en una fuerza positiva, incluyente y equitativa para todos los habitantes del mundo y al precisar valores fundamentales estimados esenciales para las relaciones Internacionales en el siglo XXI. Entre esos valores son particularmente relevantes en materia de democracia nacional, regional e internacional, los de libertad, igualdad, solidaridad, tolerancia, responsabilidad común ${ }^{17}$. En esa dirección, afirman la consolidación mundial del derecho al desarrollo de los individuos, pueblos y naciones, y reiteran el reconocimiento de la relación entre democracia, derechos humanos, desarrollo e imperio del Derecho. ${ }^{18}$

En esa tendencia globalizadora, la interdependencia de la democracia y del desarrollo, sobre la base del respeto y promoción de los derechos humanos y el Estado de Derecho, ha sido caracterizada como una de las grandes conquistas del mundo actual, en el cual el desarrollo incorpora a la democracia como su componente legitimador fundamental y la democracia se consolida y profundiza en el propio proceso de desarrollo nacional y de integración con otros Estados ${ }^{19}$.

Se ha reconocido ${ }^{20}$ que los beneficios de democratización y el desarrollo logrados por Latinoamérica en el siglo XX no favorecieron a grandes sectores de la población que son víctimas de la desigualdad y la exclusión, lo que genera inestabilidad en la región, crea un obstáculo significativo a su desarrollo, constituye una afrenta a la dignidad

\footnotetext{
${ }^{15} \mathrm{~A} / \mathrm{RES} / 51 / 240$ de 15 de octubre de 1997

${ }^{16}$ Resolución. aprobada por la Asamblea gen al de la ONU, A/RES/55/2 de 13 de septiembre de 2000.

${ }^{17}$ V. No. 5 y 6 de la Declaración del Milenio.

${ }^{18}$ V. No. III (11) Y V (23 - 24) la Declaración del Milenio. Esto es reafirmado en otras resoluciones de la Organización de las Naciones Unidas, entre ellas: V. Resolución aprobada por la Asamblea General sobre: "El derecho al desarrollo", A/RES/56/150 de 8 de febrero de 2002.

${ }^{19}$ V. La Democracia como elemento esencial del desarrollo y de la integración. Planteamiento del Presidente de la República federativa del Brasil, durante la X Cumbre Iberoamericana de Jefes de Estado y de Gobierne Panamá, 2000.

${ }^{20}$ Como un principio central de los valores de la Unión Europea para construir una sociedad más justa, el 28 de marzo de 2003 , en reunión con los miembros del Grupo de Fío, en Grecia, la Unión Europea presentó una iniciativa dirigida a impulsar, como estrategia de asociación, la cohesión social en les países de América Latina para forjar 'sociedades decentes" en donde todos los habitantes se encuentren en igualdad de condiciones para participar y aprovechar el proceso de desarrollo nacional enfrentando mejor el proceso de globalización por medio de una integración más profunda y de calidad. Speech by Han Chris Patten, CH Rio Group Ministerial - Vouliagmeni, 28 rmarch 2003 - SPEECH/03/160.
} 
humana que debilita la democracia ${ }^{21}$. Por lo que hay que construir, con reformas y procesos equitativos, sociedades democráticas más justas, pacíficas, participativas, equitativas, tolerantes e incluyentes que promuevan y protejan todos los derechos humanos civiles, políticos, económicos, sociales, culturales, incluyendo el derecho al desarrollo, derechos que son universales, interdependientes e indivisibles ${ }^{22}$.

En el sistema interamericano está reconocida la vinculación indisoluble entre el cumplimiento de los derechos humanos incluido el derecho al desarrollo y el ejercicio efectivo de la democracia ${ }^{23}$ con la convicción de que la democracia es condición ineludible para la vigencia de los derechos humanos y para establecer las bases de una convivencia social que promueva la seguridad humana ${ }^{24}$. La Carta Democrática Interamericana consigna ${ }^{25}$ que la democracia es un derecho de los pueblos y los Estados tienen la obligación de promoverla y defenderla mediante un régimen de gobierno en el cual la democracia representativa, indispensable para la estabilidad, la paz y el desarrollo integral, se refuerce y profundice con la participación, permanente, ética y responsable de la ciudadanía. Lo que contribuye a la consolidación de los valores y principios democráticos, en particular de libertad, igualdad y justicia social que son intrínsecos a la Democracia, por lo que la existencia de una sociedad democrática tiene como condición fundamental más allá de la celebración de elecciones periódicas, libres y justas, así como la pluralidad de partidos y organizaciones políticas, y la separación e independencia de los poderes públicos, la promoción y protección de los derechos humanos cuyo desarrollo y fortalecimiento la consolida. La democracia así concebida y reconocida es la base del Estado de Derecho y de los regímenes constitucionales en los Estados miembros de la Organización de los Estados Americanos y busca arraigar la cohesión social.

La Carta Democrática Interamericana y la aplicación que se está haciendo de ella orientan hacia la construcción de una democracia más moderna y participativa. En esa renovación, resurge también la importancia de la cohesión social como factor determinante de arraigamiento y de coordinación democrática al crear condiciones favorables para resolver problemas estructurales mediante una transformación de la sociedad y del Estado como proceso fundamental para mejorar las condiciones de vida de todas y todos los habitantes.

La democracia requiere actualmente de enfoques más modernos y participativos en

\footnotetext{
21 "No se puede catalogar realmente como democrático a ningún Estado que no ofrezca a la ciudadanía una salida a la pobreza. Y, a su vez, ningún país puede verdaderamente desarrollarse si su ciudadanía está excluida de poder”. ONU, Secretario General, IV conferencia Internacional de Democracias nuevas o restauradas, Cotonou, Benin, 4-6 diciembre 2000.

${ }^{22}$ III CUMBRE AMERICA LATINA Y EL CARIBE- UNION EUROPEA, Declaración de Guadalajara, No. 39, 40 y 47 -México, 28 y 29 de mayo de 2004

${ }^{23}$ V. LA DEMOCRACIA COMO MARCO en Nieto Navia (Rafael), INTRODUCCION Al SISTEMA INTERAMERICANO DE PROTECCION A LOS DERECHOS HUMANOS, PP. 35-49, Instituto Interamericano de Derechos Humanos, Pontificia Universidad Javeriana- programa de Estudios Políticos, Bogotá, Colombia, 1988.

${ }^{24}$ NO. 6 Declaración sobre los Derechos Humanos como elemento esencial de la seguridad humana, Instituto Interamericano de derechos humanos, normativa y documentos, San José, Costa Rica, 2002.

${ }^{25}$ V. Preámbulo y artículos 1 a 6, 7, 11,12,13 y 26 a 28 de la Carta Democrática Interamericana. OEA, 11 de septiembre de 2001.
} 
los que convergen criterios de capital social, cohesión, participación ciudadana y fortalecimiento del Estado para transformar la sociedad ${ }^{26}$.

La cohesión social se reconoce como aspecto fundamental para la afirmación de la democracia y el desarrollo humano, y como instrumento para la creación de una sociedad para todos y todas que sea estable, segura y justa, donde los habitantes tengan la capacidad de vivir juntos en libertad y de participar plena y responsablemente en la vida social, cultural, económica y política.

Ese fin democrático expresa, aún de manera genérica, una imagen, objetivo del proyecto de un país democrático, o de una región integrada democráticamente, a concretarse según las propias expectativas de sus respectivas sociedades o de la asociación de ellas y sus Estados, teniendo presente que el centro y sujeto principal de ese proyecto son los habitantes, las familias, las comunidades, el pueblo y que su base fundamental se encuentra en la igualdad, la libertad y la justicia social expresadas en el respeto y promoción de la dignidad humana.

Sin embargo, se constata en la mayoría de los países que hay una crisis del vínculo entre las personas y sus sociedades y estados que afecta negativamente la democracia como fundamento de la cohesión, en los mismos, por lo que hay necesidad de una democracia viva ${ }^{27}$ cuya realización progresiva promueva la Cohesión o integración social nacional y regional.

El carácter político, económico, territorial, social, cultural y ambiental de la cohesión social requiere, para su realización, de una estrategia global e integral del desarrollo humano como cuestión política fundamental que sirve de parámetro y pone en evidencia la legitimidad de la gestión pública, nacional o regional, acorde con la razón de ser del Estado democrático, sus instituciones públicas y la institucionalidad regional, y su papel esencial en la promoción y respeto de los derechos humanos y libertades fundamentales de su población ${ }^{28}$.

La cohesión social se revela como cuestión esencial para la democracia y el desarrollo integral sostenible ${ }^{29}$ al fomentar un sentimiento de pertenencia y de solidaridad entre las personas en razón de actividades, proyectos comunes, valores compartidos, y un patrimonio cultural común que incentiva la capacidad de las personas de vivir juntas y de participar plenamente en la vida social, cultural, económica y política, fundamentado en el respeto, promoción y tutela de los derechos humanos de todos,

\footnotetext{
${ }^{26}$ V. Informe Latino barómetro 2007, p. 12

${ }^{27}$ V. De la Cohesión Social a la participación democrática en UNESCO, la educación encierra un tesoro, informe a la UNESCO de la Comisión Internacional sobre la educación para el Siglo XXI, presidida por Jacques Delors. Pp.59 -79,

Ediciones UNESCO, Edición Fundación el Comercio, Quito, Ecuador, 1998.

${ }^{28}$ V. también Comité Económico y Social Europeo, DICTAMEN, 2.1 -2. 5, RES/152 “Cohesión social en América Latina y el Caribe”, Bruselas, 2 de marzo de 2004 .

${ }^{29}$ Naciones Unidas, DECLARACION SOBRE EL PROGRESO Y EL DESARROLLO EN LO SOCIAL, proclamada por la Asamblea General de las Naciones Unidas, el 11 de diciembre de 1969, resolución 2542 (XXIX), Cumbre Mundial sobre el Desarrollo Social, DECLARACION SOBRE EL DESARROLLO SOCIAL, No. 2 y Capítulo IV, Integración Social, del Programa de Acción, Copenhague, 1995, COMISION INTERNACIONAL SOBRE LA EDUCACION PARA EL SIGLO XXI, LA EDUCACION ENCIERRA UN TESORO, Informe a la UNESCO 1996, Boutique Creativa, Quito, Ecuador, 1998.
} 
bajo el imperio del Derecho, garantizando esencialmente, a los sectores humanos en situación de pobreza, desigualdad y exclusión, a que tengan iguales oportunidades para su avance social, cultural, económico y político.

La cohesión social revela así su carácter inherente y valorizador de un proceso propio de desarrollo humano sostenible que en la realidad sociológica, nos conduzca progresivamente a realizar los principios o valores de la democracia aproximándonos con certeza a una mejor sociedad y Estado humanistas, justos, estables y seguros. Objetivo cuyo logro implica actualmente tensiones con fines diferentes.

Los cambios globales son un fenómeno multifacético multidimensional que tiene como sujetos u objetos a los países y que, por un lado, parece estarse concretando más en sus aspectos de creciente interdependencia financiera, comercial y tecnológica que aumenta la participación del mercado y tiende a reducir los espacios necesarios para la consolidación de la democracia nacional al influenciar y buscar preponderancia en todos los ámbitos del desarrollo de los Estados, cuya credibilidad como promotores de dicho desarrollo humano sostenible, plantea incertidumbres en razón de las restricciones al ámbito de autonomía nacional de sus decisiones. Sin embargo, por otro lado, estos cambios han traído consigo principios éticos comunes e interrelacionados en particular sobre democracia, promoción y protección de los derechos humanos incluido el derecho al desarrollo, Estado de Derecho, solidaridad, que se reflejan en tratados internacionales, declaraciones de conferencias internacionales, en cumbres continentales, intercontinentales y de las Naciones Unidas ${ }^{30}$.

Hay coincidencia en que: "Vivimos en un mundo que cambia constantemente, donde los enlaces entre los Estados, sus economías y sus sociedades son cada vez más fuertes y complejos. Este fenómeno nos plantea un reto ineludible y urgente, y una posible forma de superar esta situación, es el concepto de unión entre Estados para trabajar conjuntamente en la solución de los problemas que los aquejan.

De todas las formas de cooperación la integración de los Estados dentro de una instancia superior es la más compleja, ya que ésta implica entrega de soberanía, de poder y de libertad de los Estados frente a instituciones supranacionales" ${ }^{\prime 31}$

\footnotetext{
${ }^{30}$ V. Resolución citada de la Comisión de Derechos Humanos, ONU; y también resolución: “Apoyo del sistema de las Naciones Unidas a los esfuerzos de los gobiernos para la promoción y la consolidación de las democracias nuevas o restauradas" A/RES/61/221 de 14 de marzo de 2007

31 ARNOLD (Christian), La Experiencia de la Unión Europea y sus anécdotas para la "Comunidad Andina de Naciones" (CAN), p. 4, Center for European Studies, Discussion Paper, C145, Bonn, Germany, 2005.
} 


\section{II.- LA DEMOCRACIA COMO INSTRUMENTO LEGITIMADOR DE LOS PROCESOS DE INTEGRACIÓN}

Se ha reconocido, en los dos Pactos Internacionales de Derechos Humanos, el derecho de libre determinación de los pueblos para "establecer libremente su condición política y proveer asimismo a su desarrollo económico social y cultural", pudiendo, al efecto "disponer libremente de sus riquezas y recursos naturales, sin perjuicio de las obligaciones que deriva de la cooperación económica internacional basada en el principio del beneficio recíproco, así como del derecho internacional. En ningún caso podrá privarse a un pueblo de sus propios medios de subsistencia." 32

El ejercicio del derecho de libre determinación es esencial para la observancia, promoción y fortalecimiento de todos los derechos humanos y está en la base del derecho al desarrollo de las personas y de los pueblos, ${ }^{33}$ siendo, entre otras, una forma de ejercicio de dicho derecho de autodeterminación la opción por la democracia ${ }^{34}$ y la libre asociación del Estado a un proceso de integración orientado a complementar ese desarrollo. ${ }^{35}$

Los Estados necesitan de estrategias para fortalecer su autonomía y credibilidad, asociándose, por medio de la integración, con otros Estados y asi en forma libre y compartida, promoverlas y mejorarlas y en forma equitativa, participar productivamente y participar activamente en el forjamiento de un sistema internacional democrático de Derecho que proteja debidamente los derechos humanos ${ }^{36}$ y muestre la coherencia en el seguimiento de los principios y valores de la democracia y del buen gobierno en el orden nacional, regional e internacional. ${ }^{37}$

\footnotetext{
${ }^{32}$ V. Artículo 1 del Pacto Internacional de Derechos Civiles y Políticos y artículo 1 del Pacto Internacional de Derechos Económicos, Sociales y Culturales.

${ }^{33}$ V. Pocar (Fausto), Pacto Internacional de Derechos Civiles y Políticos, Artículo 1., en O\JU, PREPARACION DE INFORMES SOBRE LOS DERECHOS HUMANOS.

34 “... La democracia es un valor universal basado 'en la voluntad libremente expresada de los pueblos de determinar su propio sistema político, económico, social y cultural, así como la participación plena en todos los aspectos de la vida ... si bien las democracias comparten características comunes, no existe un modelo único de democracia y que ésta no es exclusiva de ningún país o región ... la democracia, el desarrollo y el respeto de todos los derechos humanos y de las libertades fundamentales son interdependientes, se refuerzan mutuamente y constituyen principios básicos de nuestra asociación estratégica regional" No. 4 DEMOCRACIA Y DERECHOS HHMANOS, Declaración de Viena, Cuarta Cumbre Unión Europea - América Latina y el Caribe "Viena, Austria, 12 de mayo de 2006; Ver también Resolución sobre "Fortalecimiento de la función de las Naciones Unidas"A/RES/62/15C de 4 de marzo de 2008.

${ }^{35} \mathrm{~V}$. El principio de la igualdad de derechos y de la sobre determinación de los pueblos en la DECLARACION SOBRE LOS PRINCIPIOS DE DERECHO INTERNACIONAL REFERENTES A LAS RELACIONES DE AMISTAD Y A LA COOPERACION ENTRE LOS ESTADOS DE CONFORMIDAD A LA CARTA DE LAS NACIONES UNIDAS, resolución 2625 (XXV) de la Asamblea General de la ONU.

${ }^{36}$ V. Asamblea General ONU, Resolución sobre Fortalecimiento del Estado de Derecho A/RES/57/221 de 27 de febrero de 2003

${ }^{37}$ V. Poder y políticas democráticas en la globalización, en PNUD, la Democracia en América Latina - Hacia una Democracia de ciudadanas y ciudadanos, Informe del Programa de las Naciones Unidas para el Desarrollo 110, pp. 195 - 199, impreso por Word Chile S.A., 2004
} 
La cooperación internacional entre países es importante cuando tiene como objetivo común fortalecer sus democracias, compartir y complementar sus esfuerzos respectivos de desarrollo nacional, pero la consistencia y certidumbre, a largo plazo, sólo puede tener mayor certeza de viabilidad por compromisos duraderos en cuanto a integrar competencias soberanas y ejercicio de las mismas en procesos que aseguren participación y beneficio de las poblaciones que, en democracia, son los titulares del Estado y de los procesos de integración. Hay ejemplos del impacto de las políticas nacionales sobre la democracia y la integración ${ }^{38}$ y sobre la posibilidad de Estados con diferentes regímenes políticos participando en un proceso de integración. La realidad observada demuestra que la homogeneidad democrática, forma objetivos de gobiernos que favorece el avance integracionista ${ }^{39}$ hacia la posibilidad de soberanías compartidas en esquemas de cooperación transnacional, democrática e integración supranacional. ${ }^{40}$

Es decir, que la democracia y el desarrollo tienen una expresión política internacional en la decisión de los Estados de optar por la integración que, en cualquiera de sus ámbitos y expresiones, implican, más allá de la cooperación, una vinculación solidaria y más estrecha entre países en función de un proyecto común de región. Proyecto regional que se sustenta en valores y principios compartidos, por lo que tiene siempre una dimensión política con incidencia en la democracia, y en el desarrollo nacional.

En la actualidad, esa dimensión política se refleja en el objetivo del desarrollo integral sostenible con enfoque de derechos humanos por medio de la aplicación de los principios y valores democráticos y cuyo logro positivo, viabilizado por los procesos de integración, permiten aprovechar los aspectos positivos de la globalización.

Esa dimensión política es central en el nuevo diseño integracionista de Centroamérica, vigente desde 1993.

Con el Proceso de Esquipulas, ${ }^{41}$ cinco Estados Centroamericanos, por medio de sus Presidentes, se comprometieron tanto a un auténtico proceso democrático pluralista y participativo en la toma de decisiones que implique la promoción de la justicia social y el respeto de los derechos humanos, como a adoptar los acuerdos que permitan acelerar el desarrollo para alcanzar sociedades más igualitarias y libres de la miseria y la creación de un sistema de bienestar y justicia económica y social. ${ }^{42}$ Centroamérica trazó así su camino hacia la

\footnotetext{
${ }^{38}$ GIACALONE (Rita), THE IMPACT OF NEOPOLIST CIVILIAN - MILITARY COALITIONS ON REGIONAL INTEGRATION AN DEMOCRACY: THE CASE OF VENEZUELA. Journal of Political an Military Sociology, Vol. 33 No. 1, pp. 5- 8, 2005.

${ }^{39}$ V. Marin Boscan (Francisco Javier), Democracia, integración y desarrollo en América Latina ante el Tratado de Libre Comercio de las Américas (ALCA). P. 4, Centro de Informacion, estimaciones y Estudios Laborales, Universidad de Zulia. i\Maracaibo - Venezuela, 2007.

${ }^{40}$ Ver KUNHARDT /(ludger), THE GLOBAL PROLIFERACION OF REGIONAL INTEGRATION, European Experience in Worldwide Trends, p. 55, Center For European Integration Studies, Bonn, Germany, 2004.

${ }^{41}$ HERRERA CACERES (H. Roberto), DEMOCRACIA, DESARROLLO Y PAZ EN CENTROAMERICA (Las Cumbres Presidenciales, Editorial Guaymuras, Tegucigalpa, Honduras, 1989

${ }^{42}$ La relación entre democratización e integración centroamericana así como el papel central de los derechos humanos ha sido prevista expresamente en Centroamérica. V. Herrera Cáceres, ut. Supra y ARIAS CALDERON (Ricardo), El ROL DE LA COOPERACION EUROPEA EN EL PROCESO DE ESQUIPULAS, en Instituto Centroamericano de Estudios Políticos, PANORAMA CENTROAMERICANO, No. 42, p.14, Guatemala, 1996.
} 
democracia, al desarrollo y la integración, como fundamento para reconstruir y fortalecer su cohesión social, impulsando el respeto de todos los derechos humanos de los habitantes. ${ }^{43}$ Esa visión transformadora se plasmó en el Protocolo de Tegucigalpa que, como instrumento fundamental del nuevo proceso humanista de integración, vino consecuentemente a prevalecer regionalmente sobre todos los tratados, acuerdos o convenios, y a suceder internacionalmente a la Organización de Estados Centroamericanos por el Sistema de la Integración Centroamericana.

En efecto, el Protocolo de Tegucigalpa que instituyó el Sistema de la Integración Centroamericana fue adoptado por la Reunión de Presidentes Centroamericanos que se reunió en Honduras, el 13 de diciembre de 1991, en un contexto de reiteración de la importancia del "Procedimiento de Esquipulas" como necesario e indispensable para la democracia y el desarrollo sostenible de la región y orientado a la promoción integral de la persona humana para procurar el afianzamiento de la paz firme y duradera en Centroamérica asegurando condiciones de vida adecuadas a los pueblos centroamericanos mediante el desarrollo humano y la superación de las desigualdades sociales en el marco de la consolidación del Estado de Derecho, el fortalecimiento democrático y el respeto irrestricto a los derechos humanos. ${ }^{44}$ A partir del Protocolo de Tegucigalpa, la Carta de la Organización de Estados Centroamericanos (ODECA) que entró en vigencia en el 2003, institucionalizando el Sistema de la Integración Centroamericana (SICA) como organización subregional sucesora de la ODECA y del denominado Mercado Común Centroamericano: el diseño del proceso de integración ubica a la democracia como parte inseparable del desarrollo, la libertad y la paz, que constituyen el objetivo primordial del Proyecto de Región a realizarse por medio de la integración de Centroamérica. ${ }^{45}$ Ese objetivo primordial orienta hacia la ruta que debe seguir el proceso de largo plazo a ser construido por el Sistema de la Integración Centroamericana sobre la base fundamental de la tutela, respeto y promoción de todos los derechos humanos de las y los habitantes de Centroamérica, ${ }^{46}$ y como principios fundamentales armónicos e indivisibles que deben orientar las actuaciones de los Estados Centroamericanos y los órganos e instituciones del Sistema de la Integración Centroamericana. ${ }^{47}$

Con el vigente proceso regional centroamericano, la democracia se reconoce como principio aplicable al sistema de la Integración Centroamericana, centrada en el ser humano, global y equitativamente. Características que, junto con las de solidaridad e identidad, indican la dirección que debe seguir la gestión del proceso de integración, asegurando la partici-

\footnotetext{
${ }^{43}$ V. VII REUNION DE PRESIDENTES DE CENTROAMERICA, Declaración de Montelimar No. 4 y 10 (Nicaragua), 3 de abril de 1990 ; XREUNION DE PRESIDENTES DE CENTROAMERICA, Declaración de Antigua, Introducción y preámbulo, No. 1, 14 - 17, 24, ; S, 26, 27, 30, 32, 33 - 36.Antigua (Guatemala, 17 de junio de 1990; X REUNION DE PRESIDENTES DE CENTROAMERICA, Declaración de Puntarenas, preámbulo, No. 1, 31, 33, Puntarenas, Costa Rica, 17 de diciembre de1990; XI REUNION DE PRESIDENTES DE CENTROAMERICA, Declaración de San Salvador, preámbulo y No. 1,2. El Salvador 17 de Julio de 1991;

${ }^{44}$ XII REUNION DE PRESIDENTES CENTROAMERICANOS, Declaración de Tegucigalpa, preámbulo y numerales 1 a 4 . V. También Compromiso de Tegucigalpa. Honduras, 12 y 13 de diciembre de 1991.

${ }^{45}$ Artículos 1, 2, 3 literales a), b) c), d), h), i) y j) ; y artículo 4 literales a), d), h) , i) del Protocolo de Tegucigalpa

${ }^{46}$ Artículos 1, 2 literal a), Artículo 3 literal b), artículo 4 literales b) y f), artículos 5 y 6 del Protocolo de Tegucigalpa

${ }^{47}$ Artículos 9 y 10 del Protocolo de Tegucigalpa
} 
pación ciudadana; coordinando para atender integralmente, lo económico, social, cultural, político y ambiental o ecológico; y promoviendo el desarrollo humano sostenido en forma armónica y equilibrada (con tratamiento especial a países miembros de menor desarrollo relativo).

En Centroamérica la interdependencia entre democracia ${ }^{48}$ e integración resulta de la transposición meditada de mecanismos y principios vigentes de democracia, ${ }^{49}$ a lo interno de los países miembros, al proceso integrador, buscando legitimar constantemente las decisiones integracionistas y asegurar el éxito del proceso integrador, ${ }^{50}$ preservando la capacidad de acción de los gobiernos de los Estados miembros. Esa voluntad y capacidad de acción es necesaria para construir la cohesión social que requiere el fortalecimiento de la democracia promoviendo el desarrollo humano cuyas opciones endógenas se ven reducidas por la dinámica global y las tensiones que provoca entre lo nacional y lo mundial. En esa dirección se adoptó, desde 1994, una estrategia regional de desarrollo humano integral de las sociedades centroamericanas como estrategia y política central de los Estados y de la región en su conjunto que delinea políticas, programas y acciones acordes a las peculiaridades y características de Centroamérica y evidencia el proceso de integración como instrumento idóneo para realizar ese desarrollo y convertirnos en una Región de Paz, Libertad, Democracia y Desarrollo, ${ }^{51}$ en la forma indicada anteriormente. Por la integración Centroamericana, como instrumento, se busca, además de constituirse el bloque económico y financiero, asegurar espacios necesarios para la autodeterminación de Centroamérica en sus relaciones externas mediante una estrategia regional para la participación activa del aprovechamiento productivo. ${ }^{52}$ El Sistema de la Integración Centroamericana así institucionalizado representa la Comunidad Democrática de Derecho y responde a los lineamentos constitucionales de Estado democrático de los países miembros, con enfoque orientado a la promoción de la persona humana de los habitantes de Centroamérica, con órganos de todos de competencias determinadas e independientes, con una necesaria participación ciudadana permanente y responsable de la sociedad civil y con procedimientos de transparencia y rendición de cuentas. Lo anterior pone de relieve la interdependencia: entre democracia e integración y las interacciones que deberían producirse para la efectividad de la primera y el éxito de la segunda en el impulso al goce y efectivo ejercicio de los derechos humanos y las libertades fundamentales de los habitantes de la región Centroamericana, atendiendo eficazmente las necesidades de desarrollo nacional y de participación óptima en el orden internacional. La democracia es concepto y objetivo inseparable del desarrollo. La integración es instrumento para lograrlo, y su enfoque y funcionamiento democráticos legitiman las decisiones adopta-

\footnotetext{
${ }^{48}$ La democracia es considerada, en Centroamérica, como principio y objetivo inseparable del desarrollo asi como la paz y la libertad

${ }^{49}$ V.ut Supra ver asimismo principios de participación democrática, equidad, publicidad, lucha contra la corrupción, acceso a la información, rendición de cuentas, imperio del Derecho e instrumentos Jurídicos del sistema de la Integración Centroamericana.

${ }^{50}$ En aspectos atinentes a la democracia en países y en la unión Europea: ver LA DEMOCRACIA MUNDIAL EN GIDDENS (Anthony), LA TERCERA VIA Y SUS CRITICOS, pp. 170-173, Grupo Santinalla, Madrid, España, 2001.

${ }^{51}$ ALIANZA CENTROAMERICANA PARA EL DESARROLLO SOSTENIBLE, Cumbre de Presidentes Centroamericanos, Managua, Nicaragua, 12 de octubre de 1994.

${ }^{52}$ Artículos 3 literal g) y artículo 20 del Protocolo de Tegucigalpa.
} 
das para ello. La integración, a su vez, influencia positivamente la consolidación democrática y la sostenibilidad del desarrollo. La Reunión de Presidentes del Sistema de la Integración Centroamericana (Jefes de Estado y de Gobierno) han expresado reiteradamente su comprensión de que los valores y principios democráticos constituyen un patrimonio común que sirve de fundamento al Sistema de la Integración Centroamericana institucionalizado y desarrollado por tratados centroamericanos de Integración que deben relacionarse, por su compatibilidad y complementación, con la Carta Democrática Interamericana. ${ }^{53}$

En esa perspectiva de valores y de normativa funcional, es evidente la interdependencia de la democracia y la integración. Sin embargo, en el caso centroamericano, no obstante su diseño humanista de integración aún no se produce, en la medida necesaria, esa interacción para construirlo, por circunstancias propias de las actitudes y comportamientos de los gobiernos de los Estados miembros y del funcionamiento de los órganos e instituciones de la integración. ${ }^{54}$ Los objetivos de la transformación de Centroamérica como Comunidad democrática de Derecho ${ }^{55}$ se han mantenido, hasta ahora, en el plano teórico porque la mayoría de los países miembros no han logrado significativamente hacer efectiva su propia transformación interna como Estados democráticos de Derecho y no se ha producido aún el cambio de actitudes y comportamientos que se esperaba de los Gobiernos como consecuencia del paso de un viejo esquema de integración centrado en lo comercial a un nuevo esquema multidimensional que recupera el paradigma democrático constitucional y el enfoque humanista del desarrollo integral desde la perspectiva de cumplimiento de los derechos humanos. En consecuencia, tanto el modelo democrático de desarrollo humano sostenible como el de integración social y de seguridad democrática centroamericanos aún esperan de la voluntad política y buena fe para su materialización en la región y en cada uno de los Estados, lo que sigue manteniendo peligrosamente las causas de injusticia social, desigualdad y excusión que caracterizaron al proceso anterior y llevaron a la crisis centroamericana. Esta situación ha motivado que la relación de influencia recíproca entre lo nacional y lo regional continúe siendo marginal, preponderando, en las tomas de decisiones políticas regionales, una suma de varias posiciones nacionales de coyuntura o corto plazo (expresión de estructuras establece aún carentes de innovación y de compromiso permanente con la democratización), más que de una visión única para impulsar el proceso democrático de la integración y sus resultados sociales que tienen un alcance estructuralmente transformador de largo plazo, más amplio y profundo.

En suma, el formal avance jurídico y macroeconómico de los Estados de la región cen-

\footnotetext{
${ }^{53}$ Declaración Especial sobre Nicaragua, XXV reunión Ordinaria de Jefes de Estado y de Gobierno de los Países del Sistema de la Integración Centroamericana, San Salvador, el Salvador, 15 de diciembre de 2004.

${ }^{54}$ Herrera Cáceres (H. Roberto), INTEGRIDAD Y TRANSPARENCIA EN CENTROAMERICA y EN SUS RELACIONES INTERNACIONALES (Hacia un acuerdo de asociación con la Unión Europea), pp. 40 - 44, 96 114, Consejo Nacional anticorrupción, Teguci-galpa, Honduras, 2007.

${ }^{55}$ Herrera Cáceres (H. Roberto), INTEGRIDAD Y TRASNSPARENCIA EN CENTROAMERICA Y EN SUS RELACIONES INTERNACIONALES, ut. Supra.
} 
troamericana no ha sido acompañado por el buen gobierno; transparencia, rendición de cuentas y participación ciudadana activa y responsable en la integración que posibilitase realidades sociológicas y microeconómicas de mejoramiento progresivo, de la calidad de vida de los centroamericanos y centroamericanas.

De ahí los señalamientos sobre la responsabilidad de los Estados Centroamericanos por su omisión de asumir a plenitud la esencia de su proceso integrador y las ventajas que dicho proceso les ofrece para asegurar, como Región, su mejor inserción internacional, y su responsabilidad por el incumplimiento de sus obligaciones jurídicas y políticas dentro del proceso integracionista y de la estrategia de democratización centroamericana, en suma, del orden jurídico centroamericano ${ }^{56}$ y del poco aprecio del proceso integrador para el desarrollo nacional y el fortalecimiento democrático de cada uno de ellos y de la región, en su conjunto. ${ }^{57}$

Por ello, tampoco la integración aún no contribuye a fortalecer, como es la expectativa, las democracias de los Estados miembros. Para que la democracia nacional legitime e impulse el proceso de integración regional es necesario que, abandonando la retórica, se traduzca en desarrollo humano y reconozca a la integración como medio idóneo para asegurarlo. En otros términos, sólo la regionalización de efectivas políticas democráticas nacionales legitimará e impulsará los procesos de integración.

Además de una esperada y necesaria concienciación política centroamericana, hay posibilidades de cooperación ya presentes en la dirección de facilitar su materialización y la aludida interacción regional nacional mediante el fortalecimiento de "la modernización y profesionalización de la administración pública en los países Centroamericanos, lo que incluye prestar apoyo al proceso de descentralización y a los cambios organizativos derivados del proceso de integración de Centroamérica" 58 Analizados los efectos de los sistemas democráticos efectivos de cada uno de los países miembros en la creación de un ambiente positivo que promueva el avance de su proceso voluntario de integración regional, se examinará los efectos de la integración como un instrumento y proceso que favorece la consolidación de la democracia interna de cada uno de los Estados miembros de dicho proceso integrador.

\footnotetext{
${ }^{56}$ V. Herrera Cáceres (H. Roberto), IMPERIO DEL DERECHO y DESARROLLO DE LOS PUEBLOS, Corte Suprema de Justicia - Universidad Nacional Autónoma de Honduras, Litografía López, Tegucigalpa, Honduras, 2003.

${ }^{57}$ Sobre similar problemática en la comunidad Andina de Naciones, se ha expresado lo siguiente; " si se detallan los tratados en los cuales se basa comunidad andina, se logra apreciar que el proyecto integrador es todo un proceso exitoso. Existe una institucionalidad supranacional establecida y al parecer, todos los proyectos y visiones andinas están siendo cumplidos o en camino a estarlo, pues en la región andina la integración es realmente un hecho. La realidad empero, parece diferente. A pesar de la existencia de compromisos en muchas áreas, falta sus anécdotas para la "comunidad Andina de Naciones " (CAN), p. 17 Center for European Studies, Discussión paper, C145, Bonn, Germany 2005.

${ }^{58}$ Cooperación para fortalecer la modernización de la administración estatal y pública. Artículo 10 del acuerdo de dialogo político y Cooperación entre la Comunidad Europea y sus Estados miembros por una parte y las Repú-blicas de Costa Rica. El Salvador, Guatemala, Honduras, Nicaragua y Panamá, por otra parte, Roma, Italia, 15’ de diciembre de 2003.
} 


\section{III.- LA INTEGRACION COMO INSTRUMENTO Y PROCESO DE CONSOLIDACION DEMOCRATICA}

En su esencia la democracia es ética de vida para el desarrollo integral del ser humano ${ }^{59}$ que se expresa en la estrecha vinculación entre la realización de la democracia y el ejercicio efectivo de los derechos humanos incluyendo el derecho al desarrollo ${ }^{60}$ de los habitantes sobre la base de la Constitución en un país determinado y de un Tratado de Integración en una región determinada. Esa relación expresa dimensión política de los procesos democráticos de integración de Estados sobre la consolidación de sus procesos democráticos nacionales. ${ }^{61}$

La democracia tiene dimensión internacional y como tal es un principio aplicable a las organizaciones internacionales y a los Estados en sus relaciones internacionales. ${ }^{62}$ Los efectos económicos, sociales y culturales y la inteligente inserción internacional lograda por medio del proceso de integración tienen influencia positiva para legitimar regionalmente el funcionamiento democrático de las instituciones de integración. A su vez, esos efectos propician el impulso del desarrollo y el sostenimiento y la consolidación efectiva de la democracia en los estados que participan en dicho proceso de integración. En esa relación, la democracia impulsa la integración y ésta dimensión regional se legitima, a nivel nacional, por involucrar el mejoramiento de la calidad de vida de cada pueblo, consolidando así la democracia a nivel interno de cada uno de sus países miembros. ${ }^{63}$

La integración como instrumento del desarrollo humano integral está íntimamente vinculada con la democracia como forma básica de convivencia humana en libertad, igualdad, justicia y solidaridad. Por lo que la medida del éxito del proceso integrador estaría determinada por su contribución a la democratización de los Estados miembros orientada a profundizar el respeto y la valorización de la dignidad humana de los habitantes, en cada uno de dichos Estados, para consolidar esa convivencia hu-

\footnotetext{
${ }^{59} \mathrm{La}$ "democracia es un sistema de vida fundada en la libertad y el mejoramiento económico, social y cultural de los pueblos' V. Artículo 26 de la Carta Democrática Interamericana.

60 "Democracy is strongly related to the principles of human rights and cannot function 'Without assuring the full respect and protection of human dignity... Democracy is a process of constant interaction, perfection and adjustment between the basic needs of the society and the social structures in place to cater for those needs". See. Democracy in Austrian "minister for Foreign Affairs, UNDERSTANDING MAN RIGHTS, Manual on Human rights education, p.270, European Training and research Centre for Human Rights and Democracy, Vienna, Austria, 2003

${ }^{61}$ La Reforma de la Unión Europea: Una Apuesta hacia el futuro, en HORIZONTES ESTRATEGICOS DE LA INTEGRACION: OPCIONES PARA EL SIGLO XXI, Centro de Formación para la Integración Regional, Montevideo, Uruguay, 1996.

62 "Dimensión Internacional de la Democracia en numeral 24 a 27 de la Declaración Universal sobre la Democracia. Consejo Interparlamentario, Cairo, Egipto, 1997.

${ }^{63}$ V. Peña (Felix) Integración y Democracia: La Experiencia del Mercosur, Centro Internacional para la Empresa Privada. Reforma Económica Hoy, N³, pp 10-12, Washington, USA, 1997.
} 
mana con estabilidad y progreso. ${ }^{64}$

Una expresión básica de la interacción entre integración y democracia es el diálogo de los más altos representantes de los Estados sobre el proceso de democratización, reconociendo que la democracia es elemento central del desarrollo de los pueblos y que es necesario profundizar su cooperación, intercambio de experiencias y coordinación de acciones en aras de mejorar la eficiencia de los sistemas democráticos y mecanismos de integración ${ }^{65}$ para la ejecución de los compromisos y el cumplimiento de los objetivos de la integración que les permitirá alcanzar una mayor cohesión social al interior de los Estados. ${ }^{66}$

En ciertos procesos de integración, se ha verificado el impacto positivo de la integración regional sobre las democracia nacional de los Estados miembros, particularmente en prácticas de gobernabilidad políticas y la forma tradicional de la democracias. ${ }^{67}$ No obstante lo anterior, hay todavía descontento y desconfianza ciudadana en el funcionamiento democrático básico y apropiado de la mayoría de los Estados miembros del Sistema de la Integración Centroamericana y de la institucionalidad regional con respecto a la satisfacción de las necesidades colectivas de la población tal como se ha indicado en las Constituciones de la República y los tratados centroamericanos e internacionales, porque se han desviado hacia la atención preponderante de intereses de grupos y sectores dentro de los países y de la región. Con ese desvío, se ha perdido la perspectiva del proceso político integral de avance progresivo hacia el progreso y el bienestar general de la población ${ }^{68}$, en el ámbito nacional y regional, los cuales solo son punto de referencia en el discurso electoral, el de propaganda institucional y el de justificación personal. Análoga experiencia se ha observado en la Comunidad Andina de Naciones (CAN) donde se ha señalado que la ausencia de políticas sociales universales a nivel de los Estados miembros dificulta la posibilidad de desarrollar, de manera coherente, la dimensión social del proceso de integración y que: "La situación de los países miembros de la CAN se caracteriza por la persistencia de la pobreza sustentada en los grandes desniveles de la distribución de la riqueza.

\footnotetext{
${ }^{64} \mathrm{~V}$. INTEGRACION REGIONAL, COOPERACION INTERCONTINENTAL ENTRE LA UNION EUROPEA Y AMERICA LATINA Y LA CUESTION DE LA POBREZA, EL DESARROLLO Y LA DEMOCRACIA, Real 2005, Seminario Internacional, informe final, redacción Wolfang Dietrich, Cooperación Austriaca para el Desarrollo, Viena, 24 -26 de abril de 2006.

${ }^{65}$ V. Declaración de San Salvador sobre el fortalecimiento de la Gobernabilidad Democrática en Centroamérica, San Salvador, El Salvador, 24 de marzo del 2003

${ }^{66}$ V. Acuerdo No. 1 de la Declaración de la XXVIII Reunión Ordinaria de Jefes de Estado y de Gobierno de los países del sistema de la Integración Centroamericana (Declaración de Panamá); Panamá, 11 de julio de 2006

${ }^{67}$ SCHMIDT (viven) Democracy in Europe: The Impacto n Europe Integration, American Political Sciencie Association, Vol 3 No. 4, diciembre 2005.

${ }^{68}$ La política del bien común de los habitantes, si alguna vez se pensó para dar contenido a la democracia formal, ha emigrado temporalmente también de nuestras tierras ante el rechazo a reconocer los derechos humanos.
} 
Los Estados sufren escasez de ingresos fiscales y el presupuesto existente es limitado y muchas veces usado en otras áreas diferentes a la social. Parece entonces que la implementación de políticas sociales no es algo fácilmente aplicable. A pesar de que existe una formulación muy clara de objetivos sociales en el Tratado de Cartagena, se debe resaltar que a nivel comunitario, es decir, de la Comunidad, en la práctica no existe una dimensión social comunitaria desarrollada e importante que podría influir las políticas sociales nacionales. ${ }^{69}$

En relación con la mayoría de los países latinoamericanos se constata que la evolución hacia instituciones republicanas y democráticas ha sido conducida, con gran discrecionalidad, por intereses de ciertos grupos sociales o grupos de dominación que no se han sometido a los fines del Estado democrático y social y a las reglas del Estado de Derecho, y que de ello es ejemplo la corrupción que es considerado uno de los problemas más grave que obstaculiza la consolidación democrática en la región al disociar el vínculo de la convivencia social y la relación de confianza de la ciudadanía con sus gobernantes. ${ }^{70}$

La experiencia muestra que, durante varias décadas, hemos perdido oportunidades de avanzar realmente en democracia, porque en lugar de separarse de aquellos grupos o sectores, nuevas generaciones han reproducido, perfeccionado y modernizado esas actitudes contra el bien común democrático; con lo que el desarrollo humano de la mayoría de la población, la democracia redistributiva y el Estado de Derecho que los garantiza, al no existir en esta realidad en que vivimos, continuará, para esas mentes, siendo presentado como un quimérico bien colectivo del cual nunca podrán gozar las mayorías poblacionales y, con esa convicción, continuará, utilizando el proceso integrador y los foros nacionales, centroamericanos, americanos y mundiales para hacer discursos, presentando, como formas de proceso y bienestar, logros que sólo tienen sentido en relación con sus propios intereses particulares que han sobrepuesto a la soberanía del pueblo y a la soberanías individuales de la ciudadanía. ${ }^{71}$ Eso explica el claro deterioro de la institucionalidad del Estado y de la Región; de la identidad y solidaridad nacional y de la Centroamericana; de la fuerza, impulso

\footnotetext{
${ }^{69}$ Ver también Laucr (René) Las políticas sociales en la integración regional, citado en ARNOLD (Christian), La Experiencia de la Unión Europea y sus anécdotas para la "comunidad andina de Naciones" (CAN), p. 20, center for European Studies, Discussion.Germany. 2005.

${ }^{70}$ V. las raíces del desequilibrio social en América Latina y las debilidades de las sociedades latinoamericanas frente al proceso de cohesión social, en comité económico y social europeo RES/152 "cohesión social en América Latina y el Caribe,

${ }^{71}$ En relación con la Comunidad Andina de Naciones se plantea lo siguiente: "Se puede apreciar que la integración andina es más una integración de la élites que una integración de la mayoría de la población. El concepto de élites será usado en dos sentido. Primero, la integración andina es localizada hacia las élites sociales. La construcción social de las sociedades andinas es totalmente diferente, en donde se tiene una camada social alta y media alta con pocas personas ricas. Por sus propiedades, son la clase alta y media - alta la que realmente se beneficia con la integración. El hecho (el desconocimiento de la integración por grandes sectores de la población demuestra que la integración no tiene una base sustancial”. Arnold (Christian), La Experiencia de la Unión Europea y sus anécdotas para la "Comunidad Andina de Naciones" (CAN), p. 24, Center for European Studies, Discussion Paper, C145, Bonn, Germany, 2005
} 
y creatividad de los habitantes como sujetos determinantes y prioritarios en la producción y el aprovechamiento del desarrollo local, nacional y subregional; y la poca credibilidad de nuestros representantes institucionales en la escena internacional.

Los desaciertos en la gestión pública del Estado y del proceso de la integración, se encuentran en la misma confusión que ya trae el ciudadano o la ciudadana sobre el valor de la democracia para la vida en sociedad. Por eso, en ejercicio del derecho de igualdad política soberana, se debe recuperar la política del bien común, examinando crítica y constructivamente actitudes y comportamientos en sociedad civil, así como la representación que desde hace largo tiempo, se está confiriendo a quienes han hecho un modus vivendi de la democracia ficticia o de supervivencia en que vivimos en la mayoría de estados.

La democracia en el régimen de la gestión, en el funcionamiento y en los resultados del proceso de la integración centroamericana no está aún fallida y podemos recuperarla, activando la visión integradora centroamericana con la participación resuelta de los pueblos centroamericanos y la voluntad y capacidad que los Gobiernos deben demostrar, en su dimensión nacional y en la adopción y realización de actos y hechos integradores, el dinamismo sistemático de la relación recíproca entre democracia e integración y entre lo regional y lo nacional, en cumplimiento de la responsabilidad asumido como Estados dentro del Sistema de la Integración Centroamericana para convertirnos en una Región de Paz, Libertad, Democracia y Desarrollo. Para lograr la incidencia positiva de la integración sobre la consolidación de la democracia de sus países miembros ${ }^{72}$ se requiere pasar de la retórica a la real o efectiva integración democrática como Instrumento eficaz de desarrollo humano, lo que permitirá nacionalizar el avance democrático de las políticas regionales de integración. Así lo han entendido aun cuando no ejecutado, los Jefes de Estado y de Gobierno en Centroamérica al reiterar decisiones como la siguiente: "Continuar revitalizando los mecanismos de coordinación entre los países y las instituciones del SICA, garantizando la ejecución de los compromisos, el oportuno seguimiento y el cumplimiento de los objetivos de integración para alcanzar una mayor cohesión social al interior de los Estados, ampliar el intercambio comercial, velar por la debida ejecución en el marco de la normativa regional, y fortalecer la cooperación mutua. ${ }^{73}$

Ya desde el 2003, en la cooperación con la actual Unión Europea se contempla fomentar la elaboración de políticas comunes, incluyendo sectoriales, en la medida en

\footnotetext{
72 "Acordamos 1. Continuar revitalizando los mecanismos de coordinación entre los países y las instituciones del SICA, garantizando la ejecución de los compromisos, el oportuno seguimiento y el cumplimiento de los objetivos d integración para alcanzar una mayor cohesión social al interior de los Estados". Declaración de la XXVIII Reunión Ordinaria de Jefes de Estado y de Gobierno de los países del Sistema de la Integración Centroamericana, Declaración de panamá, 11 de julio de 2006.

${ }^{73}$ Art No. 1 de la Declaración de Panamá. Declaración de la XXVIII Reunión Ordinaria de Jefes de Estado y de Gobierno de los Países del Sistema de la Integración Centroamericana, Panamá, 11 de julio de 2006.
} 
que estén, contempladas en los instrumentos de la integración centroamericana ${ }^{74}$ en esa dirección, es de tomar nota de una cumbre presidencial del SICA donde se resolvió desarrollar una agenda social consistente con los avances del proceso de integración económica y el instrumental técnico-financiero para atender la problemática de las brechas sociales al interior de Centroamérica, reconociendo que: "La región Centroamericana ha experimentado en los últimos años avances sin precedentes en su proceso de integración, pero que estos logros no guardan correspondencia con la evolución de la agenda de la integración social regional, la cual requiere de un impulso mayor al que ha tenido para lograr atender los desafíos de cohesión social, desarrollo, equidad e igualdad social que son cada día más fuertes. Que si bien la responsabilidad principal de resolver los problemas de la pobreza radica en cada uno de los países centroamericanos, la persistencia y fuente común de la pobreza retrasa el desarrollo no sólo de los países, sino también del sistema de integración en su conjunto, lo que obliga a un abordaje que no puede ser sólo la suma de las políticas sociales nacionales, sino que debe obedecer a una visión y a criterios regionalmente concebidos. La sostenibilidad del proceso de integración descansa en el compromiso de reducir las asimetrías entre los países, así como a lo interno de ellos, y su fin último es el de mejorar la calidad de vida de las personas.

\footnotetext{
${ }^{74}$ V. Cooperación en materia de integración regional. Artículo 11 numeral 3 del Acuerdo de diálogo Político y Cooperación entre la Comunidad Europea y sus Estados miembros, por una parte, y las Repúblicas de Costa Rica, El Salvador, Guatemala, Honduras, Nicaragua y Panamá, por otra parte. Roma, Italia, 15 de diciembre de 2003.
} 


\section{CONCLUSIONES}

- En su esencia, la democracia es ética y su ejercicio efectivo se refleja en el buen gobierno representativo, la participación permanente y responsable de la ciudadanía en un proceso de constante interacción, ajuste y progreso hacia la libertad, la paz, el desarrollo humano integral y la cohesión social de los habitantes en una sociedad determinada.

- La cohesión social se reconoce como aspecto fundamental para la afirmación de la democracia y el desarrollo humano, y como instrumento para la creación de una sociedad para todos y todas que sea estable, segura y justa, donde los habitantes tengan la capacidad de vivir juntos en libertad y de participar plena y responsablemente en la vida social, cultural, económica y política.

- La democracia así concebida legítima tanto el proceso político nacional como el proceso político de la integración y establece, por su propia naturaleza, una interacción positiva y recíproca entre el bien público nacional y el bien público regional qué orientan la imagen objetivo del proyecto de un país democrático o de una región integrada democráticamente, a concretarse según las propias expectativas de sus respectivas sociedades o de la asociación de ellas y sus Estados, teniendo presente que el centro y sujeto principal de ese proyecto son los habitantes, las familias, las comunidades, el pueblo y que su base fundamental se encuentra en la igualdad, la libertad y la justicia social expresadas en el respeto y promoción de la dignidad humana.

- Lo anterior pone de relieve la interdependencia entre democracia e integración y las interacciones que deberían producirse para la efectividad de la primera y el éxito de la segunda en el impulso al goce y efectivo ejercicio de los derechos humanos y las libertades fundamentales de los habitantes, atendiendo eficazmente las necesidades de desarrollo nacional y de participación óptima en el orden internacional.

- La democracia es concepto y objetivo inseparable del desarrollo. La integración es instrumento para lograrlo, y su enfoque y funcionamiento democráticos legitiman 
las decisiones adoptadas para ello. La integración, a su vez, puede influenciar positivamente la consolidación democrática y la sostenibilidad del desarrollo.

- La integración como instrumento del desarrollo humano integral está íntimamente vinculada con la democracia como forma básica de convivencia humana en libertad, igualdad, justicia y solidaridad. Por lo que la medida del éxito del proceso integrador estaría determinada por su contribución a la democratización de los Estados miembros orientada a profundizar el respeto y la valorización de la dignidad humana de los habitantes para consolidar esa convivencia humana con estabilidad y progreso. Democracia e integración (instrumento del desarrollo y de la paz entre naciones libres) son dos conceptos funcionalmente inseparables cuya implementación debida los hace recíprocamente legitimadores de su respectiva interacción y realización en función del bien común de los pueblos. Por ello, así como es importante que, en el caso centroamericano, se asegure el avance de la transición democrática en cada uno de los países de la Región, esa transición opere asimismo en el Sistema de la Integración Centroamericana como expresión organizada de esa Región, facilitando así la interacción positiva y dinámica entre la democracia y la integración.

\section{BIBLIOGRAFIA}

GIACALONE (Rita), THE IMPACT OF NEOPOLIST CIVILIAN - MILITARY COALITIONS ON REGIONAL INTEGRATION AN DEMOCRACY: THE CASE OF VENEZUELA. Journal of Political an Military Sociology, Vol. 33 No. 1, pp. 5- 8, 2005.

HERRERA CACERES (H. Roberto), DEMOCRACIA, DESARROLLO Y PAZ EN CENTROAMERICA (Las Cumbres Presidenciales, Editorial Guaymuras, Tegucigalpa, Honduras, 1989

HERRERA CÁCERES, UT. SUPRA Y ARIAS CALDERON (Ricardo), EI ROL DE LA COOPERACION EUROPEA EN EL PROCESO DE ESQUIPULAS, en Instituto Centroamericano de Estudios Políticos, PANORAMA CENTROAMERICANO, No. 42, p.14, Guatemala, 1996.

KUNHARDT /(ludger), THE GLOBAL PROLIFERACION OF REGIONAL INTEGRATION, European Experience in Worldwide Trends, p. 55, Center For European Integration Studies, Bonn, Germany, 2004. 